Article

\title{
Grafting of 18 $\beta$-Glycyrrhetinic Acid and Sialic Acid onto Chitosan to Produce a New Amphipathic Chitosan Derivative: Synthesis, Characterization, and Cytotoxicity
}

\author{
Wei-Yan Quan ${ }^{1}$, Song-Zhi Kong ${ }^{1, *}$, Si-Dong $\mathrm{Li}^{1,2}{ }^{1}$, Hua-Zhong Liu ${ }^{1}$, Qian-Qian Ouyang ${ }^{2}$, Yong-Mei Huang ${ }^{2}$ \\ and Hui Luo ${ }^{2,3, *}$ \\ 1 Department of Applied Chemistry, School of Chemistry and Environmental Science, \\ Guangdong Ocean University, Zhanjiang 524088, China; quanfei183@126.com (W.-Y.Q.); \\ 13702737491@163.com (S.-D.L.); liuhzbs@163.com (H.-Z.L.) \\ 2 Marine Biomedical Research Institute, Guangdong Medical University, Zhanjiang 524023, China; \\ ouyangqianqian0426@163.com (Q.-Q.O.); huangym@gdmu.edu.cn (Y.-M.H.) \\ 3 Marine Biomedical Research Institute of Guangdong Zhanjiang, Zhanjiang 524023, China \\ * Correspondence: kongsongzhi@126.com (S.-Z.K.); luohui@gdmu.edu.cn (H.L.)
}

Citation: Quan, W.-Y.; Kong, S.-Z.; Li, S.-D.; Liu, H.-Z.; Ouyang, Q.-Q.; Huang, Y.-M.; Luo, H. Grafting of $18 \beta$-Glycyrrhetinic Acid and Sialic Acid onto Chitosan to Produce a New Amphipathic Chitosan Derivative: Synthesis, Characterization, and Cytotoxicity. Molecules 2021, 26, 452. https://doi.org/10.3390/ molecules 26020452

Academic Editor: Farid Chemat Received: 19 December 2020 Accepted: 14 January 2021 Published: 16 January 2021

Publisher's Note: MDPI stays neutral with regard to jurisdictional clai$\mathrm{ms}$ in published maps and institutional affiliations.

Copyright: () 2021 by the authors. Licensee MDPI, Basel, Switzerland. This article is an open access article distributed under the terms and conditions of the Creative Commons Attribution (CC BY) license (https:// creativecommons.org/licenses/by/ $4.0 /)$.

\begin{abstract}
Chitosan is the only cationic polysaccharide found in nature. It has broad application prospects in biomaterials, but its application is limited due to its poor solubility in water. A novel chitosan derivative was synthesized by amidation of chitosan with $18 \beta$-glycyrrhetinic acid and sialic acid. The chitosan derivatives were characterized by Fourier transform infrared spectroscopy, thermogravimetric analysis, and measurement of the zeta potential. We also investigated the solubility, cytotoxicity, and blood compatibility of chitosan derivatives. $18 \beta$-glycyrrhetinic acid and sialic acid could be grafted onto chitosan molecular chains. The thermal stability of the synthesized chitosan derivatives was decreased and the surface was positively charged in water and phosphate-buffered saline. After chitosan had been modified by $18 \beta$-glycyrrhetinic acid and sialic acid, the solubility of chitosan was improved greatly in water and phosphate-buffered saline, and percent hemolysis was $<5 \%$. Novel amphiphilic chitosan derivatives could be suitable polymers for biomedical purposes.
\end{abstract}

Keywords: chitosan; chitosan derivatives; $18 \beta$-glycyrrhetinic acid; sialic acid; cytotoxicity

\section{Introduction}

$18 \beta$-Glycyrrhetinic acid (GA) is released from glycyrrhizin through hydrolysis. It is extracted from the roots of licorice, and exhibits various anti-inflammatory [1-5], antioxidation [6-9], and antimicrobial activities [10]. GA is used widely in the pharmaceutical industry [11]. In particular, due to its anti-inflammatory and antiallergic activities, it is used against skin disorders, such as treatment of atopic dermatitis, pruritus, and acne vulgaris [12-15]. Recent studies [16,17] have shown that GA has an antiphotoaging effect, which could expand its potential application in the cosmetic field [18-20]. However, GA is poorly soluble in water with low bioavailability, and long-term use can cause hyperaldosteronism: these factors limit its application greatly. To improve the activity of GA, the structure has been modified, and good results have been achieved [21-25]. Simultaneously, it has been found that GA can target hepatocyte membranes [26]. Some studies have shown that GA, upon insertion into the molecular chains of chitosan (CS), acts as a targeted carrier to deliver drugs to the liver for therapeutic purposes [27-29].

The monosaccharide derivative sialic acid (SA) is a receptor of influenza viruses, and can prevent bacteria from invading cells. Researchers have studied the effect of SA on the immune response [30,31], anti-inflammatory actions [32-35], antibacterial actions [36], antitumor effects [37], and drug delivery [38]. SA is distributed widely in animals and microorganisms in the form of monomers and polymers [39]. Sialylation can enhance the anti-inflammatory activity of the immunoglobulin (Ig)G antibody and promote the 
escape of microorganisms from the host immune system [39]. These phenomena have made sialylation a research hotspot.

As the only cationic polysaccharide found in nature, CS has several advantages: it is nontoxic, biodegradable, and has good biocompatibility and antibacterial properties. In recent decades, it has been studied widely and deeply as a biomedical material [40]. However, its application is limited due to its many intramolecular and intermolecular hydrogen bonds, which result in the poor solubility of CS in water [41]. Several studies [42-44] have been carried out to improve the water solubility of CS by modifying its molecular structure to break the hydrogen bonds within or between CS molecules. In many of these modification studies, amphiphilic CS has been an important class of CS derivative. Hydrophobic and hydrophilic groups are introduced into the molecular structure of CS, and nanoscale micelles can be obtained through molecular self-assembly [45-49]. These types of nanoscale micelles can embed fat-soluble active substances, which improves the application range of drugs with poor solubility in water. However, few studies have involved the "grafting" of fat-soluble drugs as hydrophobic groups into CS molecular chains. This may be because the activity of fat-soluble drugs decreases (or is even lost) after grafting onto CS molecular chains, which is unfavorable for their application. Conversely, the biological activity of a drug may be unchanged (or its activity weakened only slightly) after a drug molecule is grafted onto CS molecular chains. Meanwhile, CS itself has certain biological activity, which may engender the modified product with new biological activities or synergistic effects upon modification of CS molecular chains. For example, despite being an efficacious antibacterial drug, gentamicin has been used rarely clinically because of serious drug resistance and obvious side-effects. However, the antibacterial activity of gentamicin was not weakened when it was introduced into CS molecular chains by Yan and colleagues [50]. That finding could enable gentamicin to be developed in aquaculture [51]. Protocatechuic acid, as an active substance, has antioxidant, antitumor, and neuroprotective effects. Xu et al. [52] grafted protocatechol onto carboxymethyl chitosan by $N$-(3-Dimethylaminopropyl)- $N$-ethylcarbodiimide hydrochloride/ $N$-hydroxysuccinimide (EDC/NHS) reaction to improve its antioxidant activity. It can be used as a promising antioxidant material for drug delivery and tissue engineering. Based on chitosan, Fathi et al. [53] designed methotrexate-conjugated multifunctional nanoparticles for targeted delivery of erlotinib, which has potential application in targeted therapy of ovarian cancer.

In the present study, GA and SA were incorporated into CS molecular chains to prepare an amphiphilic type of CS, which was then characterized. The cytotoxicity of the CS derivative was investigated using a human keratinocyte (HaCaT) line. Due to the introduction of active substances, it is expected that the new CS derivative could be applied in the treatment of skin burns/scalds, exogenous skin diseases, transdermal delivery of drugs, and cosmetics.

\section{Materials and Methods}

\subsection{Materials}

CS (molecular weight $=100 \mathrm{kDa}$, degree of deacetylation $>95 \%$ ) was purchased from Cool Chemistry (Beijing, China). GA (purity $>98 \%$ ) was obtained from Gansu Fanzhi Pharmaceuticals (Gansu, China). SA (purity $>98 \%$ ), N-Hydroxysuccinimide (NHS; purity $>98 \%$ ), and $N$-(3-Dimethylaminopropyl)- $N^{\prime}$-ethylcarbodiimide hydrochloride (EDC; purity $>98 \%$ ) were purchased from Aladdin (Shanghai, China). Acetic acid and other chemical reagents were from Shanghai Macklin Biochemicals (Shanghai, China). Cell culture medium (Dulbecco's modified Eagle's medium), fetal bovine serum (FBS), and trypsin were from Gibco (Billings, MT, USA). HaCaT cells were supplied by Guangzhou University of Chinese Medicine (Guangzhou, China).

\subsection{Synthesis of Chitosan-18ß-Glycyrrhetinic Acid (CS-GA) and Chitosan-Sialic Acid (CS-SA)}

The synthesis of CS-SA and CS-GA was based on a protocol described previously [35,54] with some modifications. First, $1 \mathrm{~g}$ of CS powder was dissolved in $50 \mathrm{~mL}$ of $0.1 \mathrm{M}$ 
hydrochloric acid to obtain a homogeneous CS solution $(20 \mathrm{mg} / \mathrm{mL})$. Meanwhile, GA (100 mg) was dissolved in $50 \mathrm{~mL}$ of anhydrous ethanol. Then, equal amounts of EDC and NHS (mass ratio, EDC/NHS:GA = 1.2:1) were added to the GA solution to activate the carboxyl group of GA at $60{ }^{\circ} \mathrm{C}$ and $\mathrm{pH}$ 5.0-6.0 (adjusted by PBS) for $30 \mathrm{~min}$. Next, $50 \mathrm{~mL}$ of activated GA solution was added dropwise into preheated $\left(60^{\circ} \mathrm{C}\right) \mathrm{CS}$ solution under continuous stirring for $24 \mathrm{~h}$. Finally, the synthetic mixture solution was dialyzed against distilled water using a dialysis bag (molecular weight cutoff: $3.5 \mathrm{kDa}$; Viskase, Willowbrook, IL, USA) for 3 days to remove the remaining water-soluble reagents, and then lyophilized to obtain the CS-GA product. The product, which contained GA with unreacted components, was washed several times with absolute ethanol. Then, it was dried at $60^{\circ} \mathrm{C}$ to obtain the final CS-GA conjugate. The synthesis method of CS-SA was consistent with that of CS-GA, the difference was that the CS-SA product could be obtained after freeze-drying without washing with ethanol.

\subsection{Synthesis of Sialic Acid-Chitosan-18ß-Glycyrrhetinic Acid Conjugates (SA-CS-GA)}

First, CS-GA ( $1 \mathrm{~g})$ was dissolved in $50 \mathrm{~mL}$ of distilled water to obtain a CS-GA solution. Meanwhile, SA (100 mg) was dissolved in $50 \mathrm{~mL}$ of anhydrous ethanol. Then, equal amounts of EDC and NHS (mass ratio, EDC/NHS:GA = 1.2:1) were added to the SA solution to activate the carboxyl group of $\mathrm{SA}$ at $60^{\circ} \mathrm{C}$ and $\mathrm{pH} 5.0-6.0$ (adjusted by PBS) for $30 \mathrm{~min}$. Next, activated SA solution $(50 \mathrm{~mL})$ was added dropwise into preheated $\left(60^{\circ} \mathrm{C}\right)$ CS-GA solution under continuous stirring for $24 \mathrm{~h}$. Finally, the synthetic mixture solution was dialyzed against distilled water using a dialysis bag (molecular weight cutoff: $3.5 \mathrm{kDa}$ ) for 3 days to remove the remaining water-soluble reagents and unreacted SA, and then lyophilized to obtain SA-CS-GA conjugates.

\subsection{Solubility Test}

The solubility test of CS derivatives in different solvents was based on the literature [43,44] with some modifications. Briefly, a sample $(0.1000 \mathrm{~g})$ was added to $5.00 \mathrm{~mL}$ of solvent (water or phosphate-buffered saline (PBS)) and stirred overnight at $25{ }^{\circ} \mathrm{C}$ to prepare a saturated solution with the insoluble part suspended in solution. After centrifuging the saturated solution $(5780 \times g, 10 \mathrm{~min}$, room temperature), the residual solid was washed thrice with acetone and dried in a vacuum drying oven for $24 \mathrm{~h}$ and finally weighed. The solubility was calculated as shown below:

$$
\text { Solubility }=\frac{0.1000-W}{5.00}
$$

where $W$ is the weight of the vacuum-dried residual solid (g).

\subsection{Fourier Transform Infrared (FTIR) Spectroscopy}

The sample was prepared using potassium-bromide pellets. The scanning range was $400 \mathrm{~cm}^{-1}$ to $4000 \mathrm{~cm}^{-1}$ with a resolution of $4 \mathrm{~cm}^{-1}$. Briefly, under an infrared lamp, the sample (0.20-1.50 mg) and potassium bromide (spectral grade, 200-300 mg) were placed in an agate mortar, mixed and ground for 2-3 min. After being exposed to a pressure of $20 \mathrm{MPa}$ for 1-2 $\mathrm{min}$, a 13-mm pellet was obtained.

\subsection{Thermogravimetric Analysis (TGA)}

TGA and differential thermogravimetric analysis (DTA) were undertaken with a TGA 5500 analyzer (TA Instruments, New Castle, DW, USA). Each sample weighed 2.0-2.5 mg. TGA was done between $30^{\circ} \mathrm{C}$ and $600^{\circ} \mathrm{C}$ at a heating rate of $10^{\circ} \mathrm{C} / \mathrm{min}$ in a nitrogen atmosphere.

\subsection{Measurement of the Zeta Potential (ZP)}

To determine the charge of the novel CS derivative, the ZP of the polymer was measured using Zetasizer ${ }^{\mathrm{TM}}$ Pro (Malvern Instruments, Malvern, UK). The voltage applied to the driving electrodes of the capillary electrophoresis cell was $150 \mathrm{~V}$. The capillary cell (DTS1070; 
Malvern Instruments) was rinsed with ultrapure water to ensure the stability of the measurements before each use. All experiments were conducted at $25^{\circ} \mathrm{C}$. The measurement was repeated thrice, and values presented as the mean \pm standard deviation (SD).

\subsection{Cytotoxicity Test}

The cytotoxicity of the new CS derivatives was evaluated by the Cell Counting Kit (CCK)-8 test. HaCaT cells were seeded into 96-well plates at 8000 cells/well. After $24 \mathrm{~h}$, the culture medium was aspirated and replaced by $100 \mu \mathrm{L}$ of fresh medium. Then, $10 \mu \mathrm{L}$ of CS derivatives of different concentrations (dissolved in PBS at pH 7.2) were added and cultured in a cell incubator for $24 \mathrm{~h}$. CCK-8 $(10 \mu \mathrm{L})$ was added into each well, and then the absorbance was determined at $450 \mathrm{~nm}$ after 2-h incubation. Cell viability was calculated as the ratio of absorbance of wells with polymer treatment to that of untreated wells.

\subsection{Hemolysis Test}

The hemolytic activity of CS derivatives was investigated according to the method described by Fisher and colleagues [55]. Briefly, $0.5 \mathrm{~mL}$ of CS derivatives of different concentrations (dissolved in PBS at $\mathrm{pH} 7.2$ ) were mixed and shaken gently with $2 \%$ red blood cells (RBCs; $0.5 \mathrm{~mL}$ ) and then incubated in a water bath at $37^{\circ} \mathrm{C}$ for $1 \mathrm{~h}$. Subsequently, they were centrifuged at $1000 \mathrm{rpm}$ for $5 \mathrm{~min}$ at room temperature. Next, $100 \mu \mathrm{L}$ was removed and placed in 96-well plates. The absorbance was detected at $540 \mathrm{~nm}$ with a microplate reader (DNM-9602; Perlong, Beijing, China). Water and PBS were used as positive and negative controls, respectively. Three parallels were set for each sample. Percent hemolysis was calculated using the following formula:

$$
\text { Percent hemolysis }=\frac{A_{s}-A_{n}}{A_{p}-A_{n}} \times 100 \%
$$

where $A_{S}$ is the absorption value of the sample, $A_{n}$ is the absorption value of the negative control, and $A_{p}$ is the absorption value of the positive control.

\subsection{Statistical Analyses}

Data are presented as the mean \pm standard deviation (SD). Statistical analyses were undertaken by the Student's $t$-test using the statistical software Prism 8.0 (GraphPad, San Diego, CA, USA). $p<0.05$ was considered statistically significant.

\section{Results and Discussion}

\subsection{Synthesis of Novel CS Derivatives}

EDC/NHS chemistry is used extensively to couple two proteins, haptens to carrier proteins, surface molecule attachment and a host of other applications. Practically, any two molecules having a carboxyl group and amine group can be conjugated by this chemistry. The EDC/NHS coupling reaction is dependent upon temperature, $\mathrm{pH}$, and the steric effect [56]. The optimum reaction conditions for our synthesis were $\mathrm{pH}$ between 5.0 and 6.0 and temperature at $60^{\circ} \mathrm{C}$ below the boiling point of ethanol. In the presence of EDC/NHS, the amino group on CS molecular chains reacts with the carboxyl group on GA or sialic acid SA, and is exhibited in Figure 1A. First, the carboxyl group of GA or SA (a) reacts with EDC to form intermediate (b). The latter reacts with NHS to obtain the NHS active ester (c). Then, (c) reacts with the primary amino groups of CS to obtain CS-GA or CS-SA (d). Additionally, GA and SA can be grafted onto CS molecular chains by amidation to obtain amphiphilic CS (Figure 1B). 


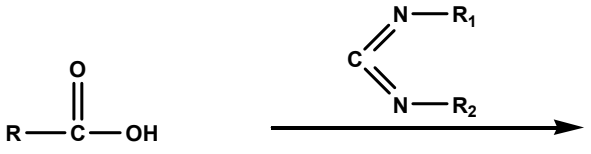

(a)

(A)

(GA or SA)
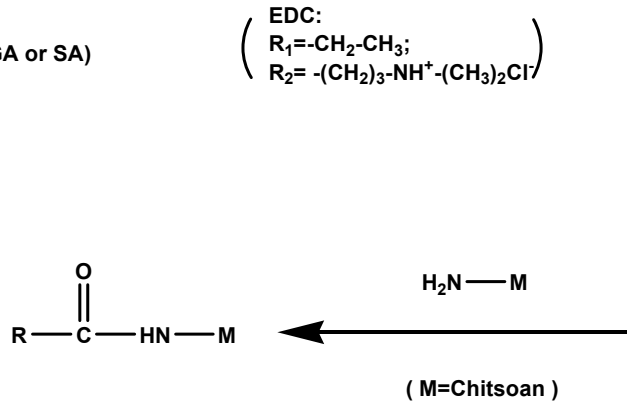

(d)<smiles>[R]N=C(N[R])OC([R])=O</smiles>

(b)<smiles>O=C1CCC(=O)N1O</smiles>

(NHS)<smiles>[R]C(=O)ON1C(=O)CCC1=O</smiles>

(c)

(B)

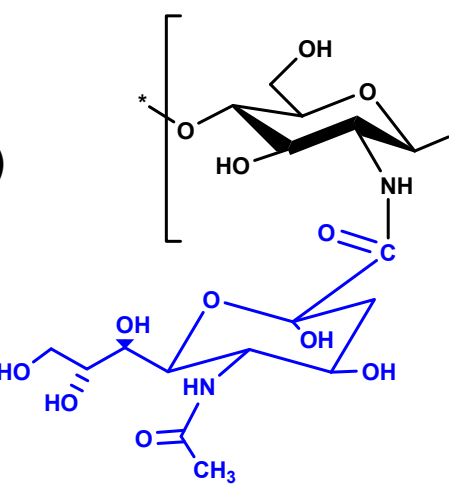

(SA)

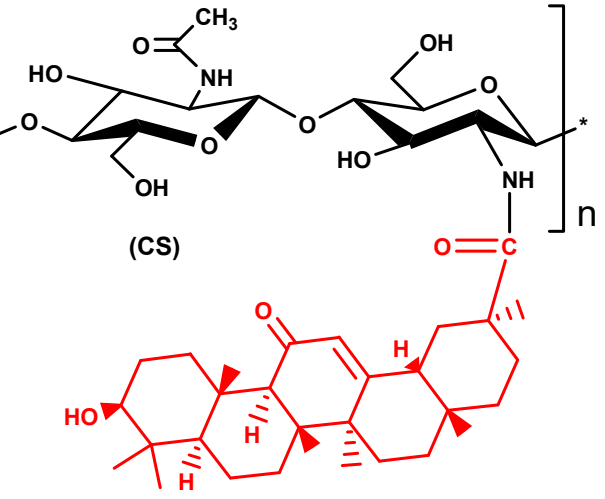

(GA)

(SA-CS-GA)

Figure 1. Graft mechanism of chitosan (CS) and 18ß-glycyrrhetinic acid (GA) or sialic acid (SA) in the presence of $N$-(3-Dimethylaminopropyl)- $N$-ethylcarbodiimide hydrochloride $/ N$ hydroxysuccinimide (EDC/NHS) (A); molecular structure of amphiphilic chitosan (B).

\subsection{Solubility of Novel CS Derivatives}

The solubility of CS derivatives in deionized water and PBS at different $\mathrm{pH}$ is shown in Table 1. Amphiphilic CS derivatives had good solubility in water and PBS at different $\mathrm{pH}$ (>20 mg/mL). GA- or SA-grafted CS derivatives also had good solubility in deionized water (>20 mg/mL), but the solubility in PBS was significantly lower than that in deionized water; nevertheless, the solubility in $\mathrm{PBS}$ at $\mathrm{pH}=4.0$ was higher than that in $\mathrm{PBS}$ at $\mathrm{pH}=7.2$. Hence, the solubility of GA- or SA-grafted CS derivatives was improved compared with that of CS, which was not soluble in water and slightly soluble in acidic PBS. After grafting of GA and SA onto the molecular chains of CS, the solubility in water was improved greatly. Also, the solubility in PBS was significantly higher than that of GA- or SA-grafted CS derivatives. 
Table 1. Solubility of novel chitosan derivatives. Data are presented as mean \pm SD of three independent experiments.

\begin{tabular}{cccc}
\hline \multirow{2}{*}{ Sample } & \multicolumn{3}{c}{ Solubility $(\mathbf{m g} / \mathbf{m L})$} \\
\cline { 2 - 4 } & Water & PBS $(\mathbf{p H}=\mathbf{7 . 2})$ & PBS $(\mathbf{p H}=\mathbf{4 . 0})$ \\
\cline { 2 - 4 } CS & 0 & 0 & $1.36 \pm 0.25$ \\
CS-SA & $>20.00$ & $5.97 \pm 0.32$ & $12.39 \pm 0.30$ \\
CS-GA & $>20.00$ & $5.65 \pm 0.37$ & $9.72 \pm 0.28$ \\
SA-CS-GA & $>20.00$ & $>20.00$ & $>20.00$ \\
\hline
\end{tabular}

\subsection{FTIR Spectroscopy of Novel CS Derivatives}

To verify that SA and GA had been introduced into CS chains, FTIR spectroscopy of SA, GA, CS, SA-CS, CS-GA, and SA-CS-GA was employed to characterize intermolecular conformational changes. The characteristic absorption bands of SA (Figure 2A) were 1725 and $1655 \mathrm{~cm}^{-1}$, which represented the stretching vibration of the carbonyl group in carboxyl groups and amide groups, respectively. However, in the FTIR spectra of GA (Figure 2B), the characteristic absorption bands associated with the stretching vibration of the carbonyl group in carboxyl groups and ketone groups appeared at 1704 and $1664 \mathrm{~cm}^{-1}$, respectively. CS displayed a weak absorption peak at $1655 \mathrm{~cm}^{-1}$ (amide I band) and a relatively strong absorption peak at $1598 \mathrm{~cm}^{-1}$ (amide II band), which was attributed to the plentiful free amine groups in CS (Figure 2C). In contrast with CS, all of the grafted products, CS-SA (Figure 2D), CS-GA (Figure 2E), and SA-CS-GA (Figure 2F) exhibited an enhanced absorption peak at $1623 \mathrm{~cm}^{-1}$ (amide I) and the absorption peak of amide II appeared at $1525 \mathrm{~cm}^{-1}$. Simultaneously, the absorption bands at 1725 and $1704 \mathrm{~cm}^{-1}$ derived from the carboxyl groups of SA and GA disappeared. Furthermore, the absorption peaks of amide I and amide II of all CS-grafted products strengthened and shifted slightly to lower wavenumbers. These phenomena were consistent with results from other studies $[54,57]$. The changes in the FTIR spectra of all CS-grafted products suggested that SA and GA were conjugated to the molecular chains of CS by the formation of amide linkages.

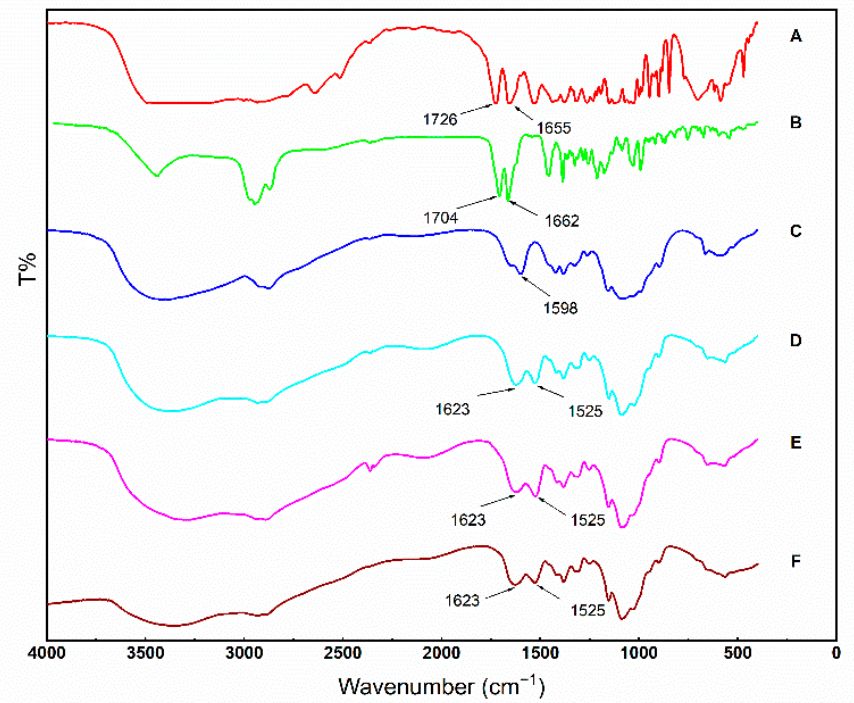

Figure 2. FTIR spectra of sialic acid (A), glycyrrhetinic acid (B), chitosan (C), sialic acid-grafted chitosan (D), glycyrrhetinic acid-grafted chitosan (E), sialic acid- and glycyrrhetinic acid-grafted chitosan (F).

\subsection{Thermal Stability of Novel CS Derivatives}

Water-absorption and degradation behavior of polymers can be evaluated by TGA [58]. Thermal degradation behavior of CS and its novel derivatives displayed two stages upon heating from $30{ }^{\circ} \mathrm{C}$ to $600{ }^{\circ} \mathrm{C}$ (Figure 3A). The first stage was the weight loss of bound 
water and unbound water of CS molecular chains. The content of bound water and unbound water in CS (11.6\%) was lower than that in GA- or SA-grafted CS derivatives and amphiphilic CS derivatives (CS-SA, 16.7\%; CS-GA, 15.9\%; SA-CS-GA, 14.0\%) (Figure 3A). This phenomenon was due to the stronger force of hydrogen bonding within or between the molecules of CS, which reduced the content of bound water and unbound water. However, after modification by hydrophobic and hydrophilic groups, the hydrogen bond of CS molecules was destroyed and, thus, it was easier to absorb water. The DTA curves of CS and its derivatives are shown in Figure 3B. The temperature corresponding to the maximum weight loss of CS and CS-GA was similar (48.0 and $47.2^{\circ} \mathrm{C}$, respectively) (Table 2). However, the temperature corresponding to the maximum weight loss of CS-SA and SA-CS-GA increased to 53.8 and $51.8^{\circ} \mathrm{C}$, respectively. The possible reason for this finding was that the content of bound water increased with the increase in the number of hydrophilic groups, and decreased with the increase in the number of hydrophobic groups.

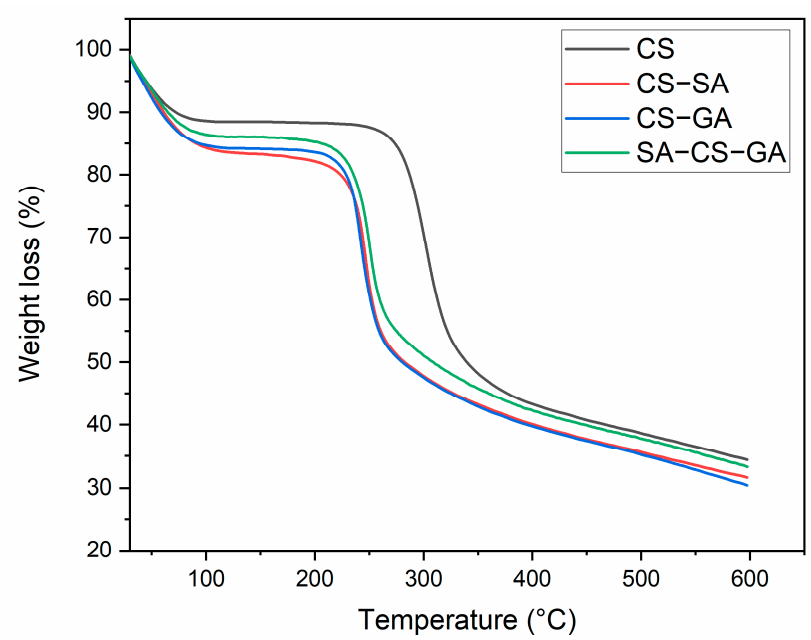

(A)

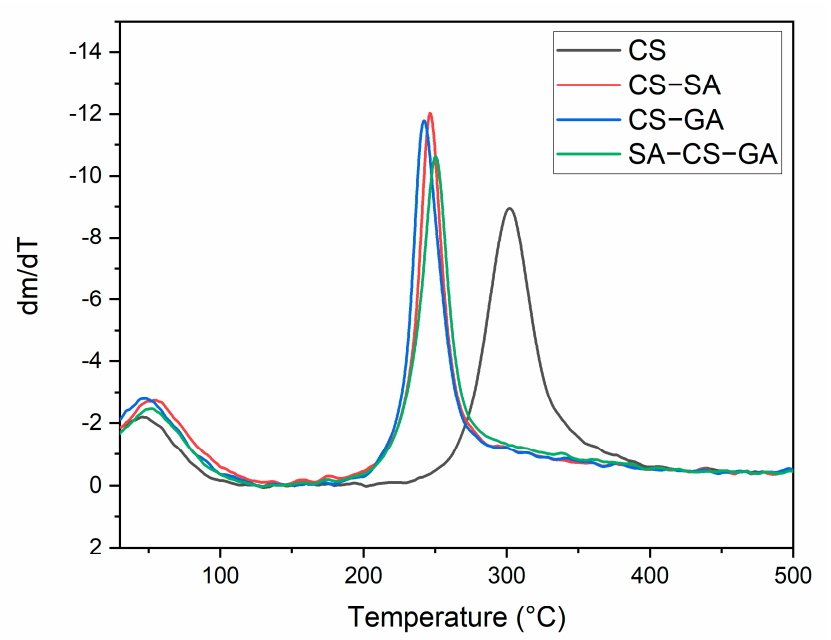

(B)

Figure 3. Thermogravimetric (TG) (A) and differential thermogravimetric analysis (DTA) (B) curves of chitosan (CS), chitosansialic acid (CS-SA), chitosan-18 $\beta$-glycyrrhetinic acid (CS-GA), and sialic acid-chitosan-18 $\beta$-glycyrrhetinic acid (SA-CS-GA).

Table 2. Characteristic temperatures of thermal degradation of CS and its derivatives.

\begin{tabular}{ccccc}
\hline \multirow{2}{*}{ Samples } & \multicolumn{3}{c}{ First Stage } & \multicolumn{3}{c}{ Second Stage } \\
\cline { 2 - 5 } & $\mathbf{T}_{\mathbf{p}} /{ }^{\circ} \mathbf{C}$ & $\mathbf{T}_{\mathbf{0}} /{ }^{\circ} \mathbf{C}$ & $\mathbf{T}_{\mathbf{p}} /{ }^{\circ} \mathbf{C}$ & $\mathbf{T}_{\mathbf{f}} /{ }^{\circ} \mathbf{C}$ \\
\hline CS & 48.0 & 279.9 & 301.9 & 327.9 \\
CS-SA & 53.8 & 235.1 & 246.4 & 261.7 \\
CS-GA & 47.2 & 231.6 & 242.2 & 259.5 \\
SA-CS-GA & 51.8 & 234.0 & 250.3 & 270.1 \\
\hline
\end{tabular}

The second stage was the degradation of CS molecular chains. Degradation of CS and its derivatives took one step (Figure 3). The characteristic temperatures of the degradation reaction are given in Table 2 , where $T_{0}$ is the temperature at which degradation starts, $T_{p}$ is the temperature at which maximum degradation occurs, and $\mathrm{T}_{\mathrm{f}}$ is the temperature at which degradation is complete. Compared with CS, the characteristic temperatures of $\mathrm{CS}$ derivatives stated above were reduced to a certain extent. However, the characteristic degradation temperatures of CS-GA were slightly lower than that corresponding to CS-SA. The $\mathrm{T}_{0}$ of SA-CS-GA was between the $\mathrm{T}_{0}$ of GA- or SA-grafted CS derivatives. However, the $\mathrm{T}_{\mathrm{p}}\left(250.3^{\circ} \mathrm{C}\right)$ and $\mathrm{T}_{\mathrm{f}}\left(270.1^{\circ} \mathrm{C}\right)$ of SA-CS-GA was higher than those of GA- or SA-grafted CS. These results indicated that GA and SA had been grafted onto CS molecular chains, and resulted in a decrease in the thermal stability of CS. 


\subsection{ZP of Novel CS Derivatives}

$\mathrm{ZP}$ is related to the electrokinetic behavior of the material molecules [59]. The ZP of $\mathrm{CS}$ and three CS derivatives in PBS of different $\mathrm{pH}$ is shown in Table 3. The ZP of CS and its derivatives was positive at $\mathrm{pH} 4.0$, indicating that the surface of CS and CS derivatives was positively charged (which is caused by the primary amino group on CS molecular chains). At $\mathrm{pH}$ 7.2, negative ZP of CS was determined, which was caused by deprotonation. At $\mathrm{pH} 4.0$, the ZP of CS was higher than that of modified CS, indicating that the number of primary amino residues in modified CS decreased, which demonstrated (indirectly) the amidation reaction. The $\mathrm{ZP}$ of the three $\mathrm{CS}$ derivatives at $\mathrm{pH}=4.0$ was higher than that at $\mathrm{pH}=7.2$, which was due to protonation of the primary amino group. The lower the $\mathrm{pH}$, the higher the ZP $[58,60]$, and our results were consistent with this general rule.

Table 3. Zeta potential of novel chitosan derivatives at $\mathrm{pH}=4.0$ and $\mathrm{pH}=7.2 \mathrm{in}$ PBS. Data are presented as mean $\pm \mathrm{SD}$ of 3 independent experiments.

\begin{tabular}{ccc}
\hline \multirow{2}{*}{ Sample } & \multicolumn{2}{c}{ Zeta Potential (mV) } \\
\cline { 2 - 3 } & $\mathbf{p H}=\mathbf{4 . 0}$ & $\mathbf{p H}=\mathbf{7 . 2}$ \\
\hline CS & $28.40 \pm 1.13$ & $-3.59 \pm 0.25$ \\
CS-SA & $24.41 \pm 1.69$ & $8.12 \pm 0.86$ \\
CS-GA & $22.12 \pm 0.54$ & $8.64 \pm 1.56$ \\
SA-CS-GA & $8.34 \pm 0.84$ & $4.13 \pm 0.87$ \\
\hline
\end{tabular}

\subsection{Cytotoxicity of Novel CS Derivatives}

The cytotoxicity and blood compatibility of materials are essential indices for application in biological fields [59]. The toxicity of novel CS derivatives against $\mathrm{HaCaT}$ cells is shown in Figure 4. The viability of HaCaT cells treated with different concentrations of CS-GA, CS-SA, and SA-CS-GA for $24 \mathrm{~h}$ was not significantly different compared with that in the control group. These results showed that CS derivatives had no toxic or side effects on $\mathrm{HaCaT}$ cells.

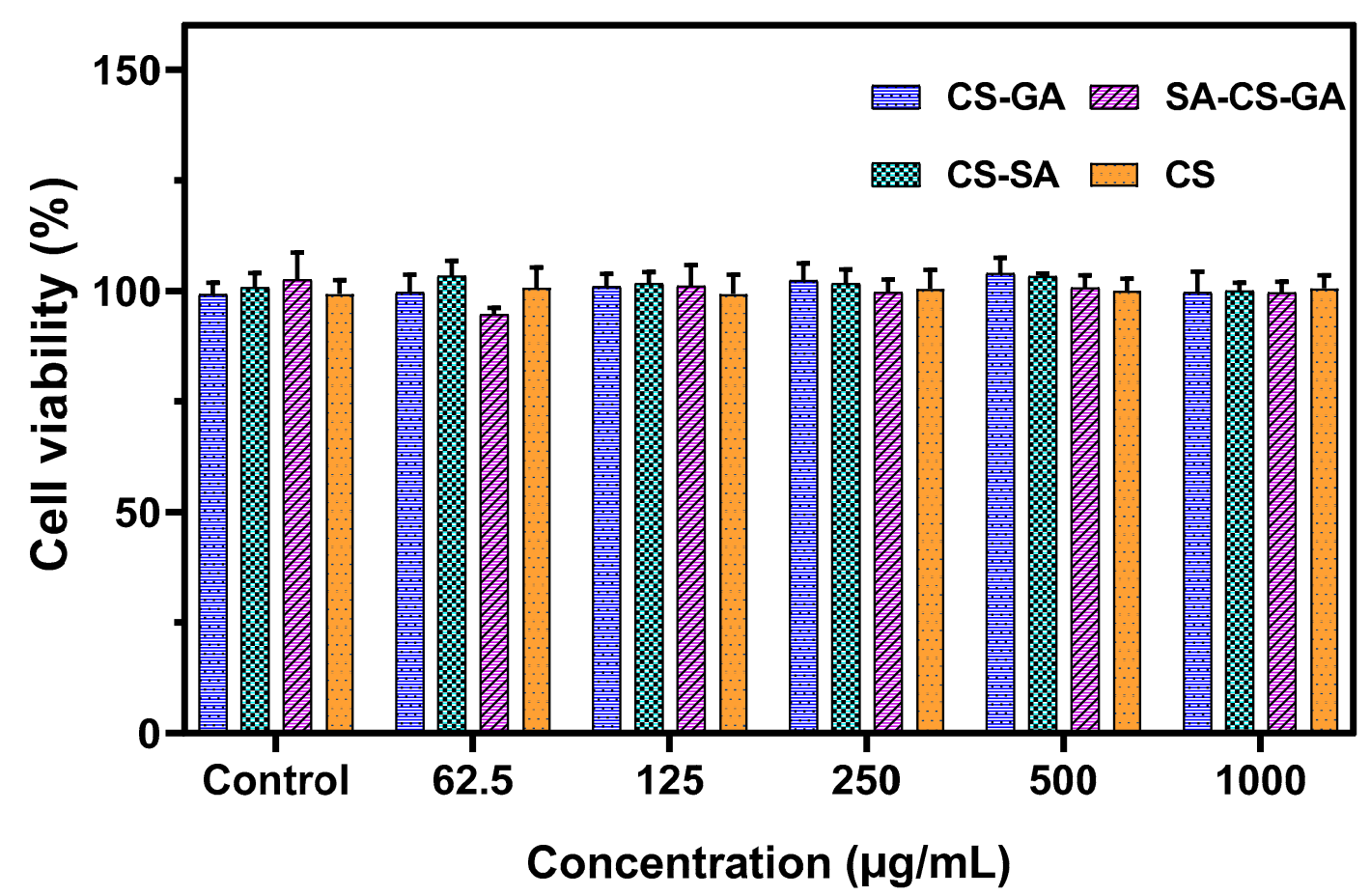

Figure 4. Viability of HaCaT cells after 24-h exposure to novel chitosan derivatives at different concentrations. Data are presented as mean \pm SD. 
A hemolysis test can be used to evaluate the blood compatibility of biomaterials [61]. Percent hemolysis $<5 \%$ meets the requirements for application of biological materials in medicine. Evaluation of blood compatibility of CS derivatives of different concentrations is shown in Figure 5. Significantly different from water-treated RBCs, no obvious rupture of RBCs was found in samples treated with CS-GA, CS-SA, and SA-CS-GA. Similar to samples treated by PBS, percent hemolysis was $<5 \%$ within the concentration range, and there was no significant difference between the groups of modified CS derivatives. These results showed that the modified CS did not damage RBCs when the concentration was $<500 \mu \mathrm{g} / \mathrm{mL}$. In addition, compared with CS-GA and CS-SA, SA-CS-GA had lower percent hemolysis at a higher concentration and better blood compatibility.

(A)

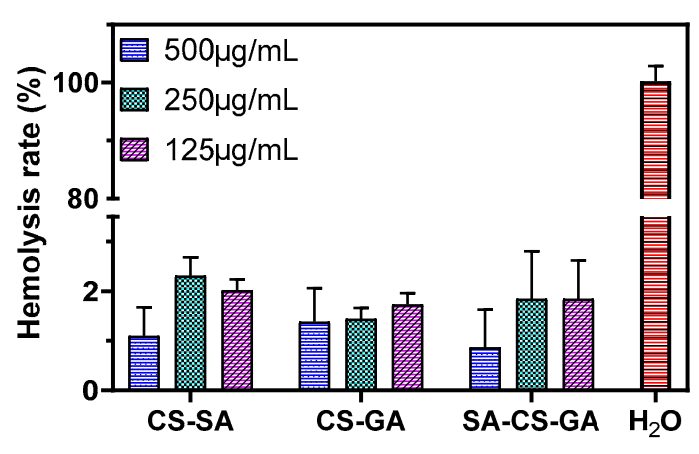

(B)

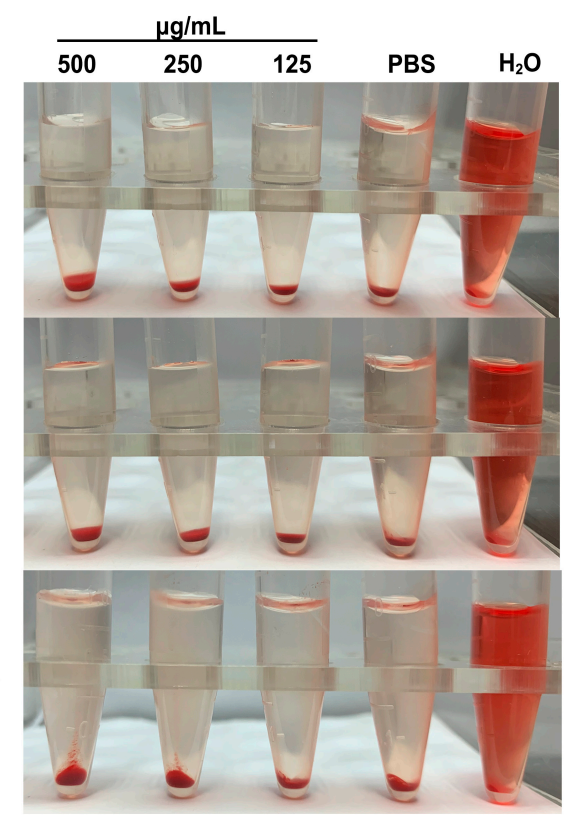

Figure 5. Hemocompatibility of novel chitosan derivatives at different concentrations. (A), hemolysis rate; (B), hemolysis photograph. Data are presented as mean \pm SD of three independent experiments.

\section{Conclusions}

GA and SA were grafted onto CS molecular chains by amidation. Compared with pure CS, due to the destruction of intramolecular and intermolecular hydrogen bonds, the thermal stability of CS derivatives decreased, and the solubility in water and PBS was increased considerably. The unreacted primary amino groups in the CS molecular chains made the CS derivatives' surface positively charged, and the ZP of amphiphilic chitosan was lower than that of others. The novel CS derivatives we synthesized were not toxic to keratinocytes and had good blood compatibility. The synthesized CS could be applied for skin repair and targeted delivery of drugs.

Author Contributions: W.-Y.Q., S.-Z.K. and S.-D.L. conceived and designed the structure of the manuscript. W.-Y.Q. wrote the manuscript. Q.-Q.O., Y.-M.H. helped in manuscript preparation. H.-Z.L. improved the manuscript. H.L. provided comments. All authors have read and agreed to the published version of the manuscript.

Funding: This work was supported by the National Natural Science Foundation of China (81803684), Natural Science Foundation of Guangdong Province (2018A030313416), Science and Technology Program of Guangdong Province (2019B090905011), the Key Laboratory of Zhanjiang for R\&D Marine Microbial Resources in the Beibu Gulf Rim (2012E02), and the Public Service Platform of South China Sea for R\&D Marine Biomedicine Resources (2017C8A). 
Institutional Review Board Statement: The red blood cells used in experiment were obtained from a common New Zealand Rabbit (purchased from Guangdong Medical Experimental Animal Center, production certificate No. SCXK (Yue) 2019-0035). All procedures for animal handling and care were done in compliance with the relevant guidelines and regulations on Scientific and Ethical Care and Use of Experimental Animal of Guangdong Ocean University (Laboratory Animal Use Permit No. SYXK (Yue) 2019-0204). All experiments were carried out minimizing the numbers of animals used and their suffering by the procedures used in the present study.

Informed Consent Statement: Not applicable.

Data Availability Statement: The data presented in this study are available on request from the corresponding author.

Conflicts of Interest: The authors declare no conflict of interests.

Sample Availability: Samples of the compounds are not available from the authors.

\section{References}

1. Lee, J.S.; Kwon, M.J.; Kwon, S.H.; Kim, J.; Moon, J.Y.; Cho, Y.C.; Shin, J.W.; Lee, J.S.; Sohn, N.W. Effects of $18 \beta$-glycyrrhetinic acid on pro-inflammatory cytokines and neuronal apoptosis in the hippocampus of lipopolysaccharide-treated mice. Korea J. Herbol. 2016, 31, 73-81. [CrossRef]

2. Finney, R.S.; Somers, G.F. The antiinflammatory activity of glycyrrhetinic acid and derivatives. J. Pharm. Pharmacol. 1958, 10, 613-620. [CrossRef] [PubMed]

3. Finney, R.S.; Somers, G.F.; Wilkinson, J.H. The pharmacological properties of glycyrrhetinic acid: A new anti-inflammatory drug. J. Pharm. Pharmacol. 1958, 10, 687-695. [CrossRef] [PubMed]

4. Maitraie, D.; Hung, C.-F.; Tu, H.-Y.; Liou, Y.-T.; Wei, B.-L.; Yang, S.-C.; Wang, J.-P.; Lin, C.-N. Synthesis, anti-inflammatory, and antioxidant activities of 18 beta-glycyrrhetinic acid derivatives as chemical mediators and xanthine oxidase inhibitors. Bioorg. Med. Chem. 2009, 17, 2785-2792. [CrossRef]

5. Xiao, Y.; Xu, J.; Mao, C.; Jin, M.; Wu, Q.; Zou, J.; Gu, Q.; Zhang, Y.; Zhang, Y. 18 beta-Glycyrrhetinic Acid Ameliorates Acute Propionibacterium acnes-induced Liver Injury through Inhibition of Macrophage Inflammatory Protein-1 alpha. J. Biol. Chem. 2010, 285, 1128-1137. [CrossRef]

6. Cao, D.H.; Wu, Y.H.; Jia, Z.F.; Zhao, D.; Zhang, Y.Y.; Zhou, T.Y.; Wu, M.H.; Zhang, H.J.; Tsukamoto, T.; Oshima, M.; et al. 18 beta-glycyrrhetinic acid inhibited mitochondrial energy metabolism and gastric carcinogenesis through methylation-regulated TLR2 signaling pathway. Carcinogenesis 2019, 40, 234-245. [CrossRef]

7. Agarwal, M.K.; Iqbal, M.; Athar, M. Inhibitory effect of 18 beta-glycyrrhetinic acid on 12-O-tetradecanoyl phorbol-13-acetateinduced cutaneous oxidative stress and tumor promotion in mice. Redox Rep. 2005, 10, 151-157. [CrossRef]

8. Yamaguchi, H.; Yu, T.; Kidachi, Y.; Akitaya, T.; Yoshida, K.; Kamiie, K.; Noshita, T.; Umetsu, H.; Ryoyama, K. Selective toxicity of glycyrrhetinic acid against tumorigenic $\mathrm{r} / \mathrm{m}$ HM-SFME-1 cells is potentially attributed to downregulation of glutathione. Biochimie 2011, 93, 1172-1178. [CrossRef]

9. Chen, S.; Zou, L.; Li, L.; Wu, T. The Protective Effect of Glycyrrhetinic Acid on Carbon Tetrachloride-Induced Chronic Liver Fibrosis in Mice via Upregulation of Nrf2. PLoS ONE 2013, 8, e53662. [CrossRef]

10. Huang, L.R.; Hao, X.J.; Li, Q.J.; Wang, D.P.; Zhang, J.X.; Luo, H.; Yang, X.S. 18ß-Glycyrrhetinic Acid Derivatives Possessing a Trihydroxylated A Ring Are Potent Gram-Positive Antibacterial Agents. J. Nat. Prod. 2016, 79, 721-731. [CrossRef]

11. Wu, F.; Li, X.C.; Jiang, B.; Yan, J.Y.; Zhang, Z.H.; Qin, J.; Yu, W.J.; Gao, Z.Q. Glycyrrhetinic Acid Functionalized Nanoparticles for Drug Delivery to Liver Cancer. J. Biomed. Nanotechnol. 2018, 14, 1837-1852. [CrossRef] [PubMed]

12. Saeedi, M.; Morteza-Semnani, K.; Ghoreishi, M.R. The treatment of atopic dermatitis with licorice gel. J. Derm. Treatm. 2003, 14, 1-3. [CrossRef] [PubMed]

13. Abramovits, W.; Boguniewicz, M. A multicenter, randomized, vehicle-controlled clinical study to examine the efficacy and safety of MAS063DP (Atopiclair) in the management of mild to moderate atopic dermatitis in adults. J. Drugs Dermatol. 2006, 5, 236-244. [PubMed]

14. Boguniewicz, M.; Zeichner, J.A.; Eichenfield, L.F.; Hebert, A.A.; Jarratt, M.; Lucky, A.W.; Paller, A.S. MASO63DP is effective monotherapy for mild to moderate atopic dermatitis in infants and children: A multicenter, randomized, vehicle-controlled study. J. Pediatr. 2008, 152, 854-859. [CrossRef] [PubMed]

15. Akasaka, Y.; Yoshida, T.; Tsukahara, M.; Hatta, A.; Inoue, H. Glycyrrhetinic acid prevents cutaneous scratching behavior in mice elicited by substance P or PAR-2 agonist. Eur. J. Pharmacol. 2011, 670, 175-179. [CrossRef] [PubMed]

16. Kong, S.-Z.; Chen, H.-M.; Yu, X.-T.; Zhang, X.; Feng, X.-X.; Kang, X.-H.; Li, W.-J.; Huang, N.; Luo, H.; Su, Z.-R. The protective effect of 18 beta-Glycyrrhetinic acid against UV irradiation induced photoaging in mice. Exp. Gerontol. 2015, 61, 147-155. [CrossRef] [PubMed]

17. Kowalska, A.; Kalinowska-Lis, U. 18 beta-Glycyrrhetinic acid: Its core biological properties and dermatological applications. Int. J. Cosmet. Sci. 2019, 41, 325-331. [CrossRef] 
18. Couteau, C.; Chauvet, C.; Paparis, E.; Coiffard, L.J. Influence of certain ingredients on the SPF determined in vivo. Arch. Dermatol. Res. 2012, 304, 817-821. [CrossRef]

19. Couteau, C.; Chauvet, C.; Paparis, E.; Coiffard, L.J. UV filters, ingredients with a recognized anti-inflammatory effect. PLoS ONE 2012, 7, e46187. [CrossRef]

20. Frikeche, J.; Couteau, C.; Roussakis, C.; Coiffard, L.J.M. Research on the immunosuppressive activity of ingredients contained in sunscreens. Arch. Dermatol. Res. 2015, 307, 211-218. [CrossRef]

21. Guan, Q.; Zhang, X.; Zhang, Y.; Yu, X.; Zhang, W.; Wang, L.; Sun, S.; Li, X.; Wang, Y.; Lv, S.; et al. Design, synthesis, and characterization of glycyrrhetinic acid-mediated multifunctional liver-targeting polymeric carrier materials. J. Mater. Res. 2020, 35, 1236-1248. [CrossRef]

22. Huang, M.; Gong, P.; Wang, Y.; Xie, X.; Ma, Z.; Xu, Q.; Liu, D.; Jing, Y.; Zhao, L. Synthesis and antitumor effects of novel $18 \beta$-glycyrrhetinic acid derivatives featuring an exocyclic $\alpha, \beta$-unsaturated carbonyl moiety in ring A. Bioorg. Chem. 2020, 103, 104187. [CrossRef] [PubMed]

23. Markov, A.V.; Sen'kova, A.V.; Popadyuk, I.I.; Salomatina, O.V.; Logashenko, E.B.; Komarova, N.I.; Ilyina, A.A.; Salakhutdinov, N.F.; Zenkova, M.A. Novel 3'-Substituted-1' $2^{\prime}, 4^{\prime}$-Oxadiazole Derivatives of 18 beta H-Glycyrrhetinic Acid and Their O-Acylated Amidoximes: Synthesis and Evaluation of Antitumor and Anti-Inflammatory Potential In Vitro and In Vivo. Int. J. Mol. Sci. 2020, 21, 3511. [CrossRef] [PubMed]

24. Markov, A.V.; Sen'kova, A.V.; Salomatina, O.V.; Logashenko, E.B.; Korchagina, D.V.; Salakhutdinov, N.F.; Zenkova, M.A. Trioxolone Methyl, a Novel Cyano Enone-Bearing 18 beta H-Glycyrrhetinic Acid Derivative, Ameliorates Dextran Sulphate Sodium-Induced Colitis in Mice. Molecules 2020, 25, 2406. [CrossRef]

25. Yang, Y.; Zhu, Q.; Zhong, Y.; Cui, X.; Jiang, Z.; Wu, P.; Zheng, X.; Zhang, K.; Zhao, S. Synthesis, anti-microbial and antiinflammatory activities of 18 beta-glycyrrhetinic acid derivatives. Bioorg. Chem. 2020, 101. [CrossRef]

26. Negishi, M.; Irie, A.; Nagata, N.; Ichikawa, A. Specific binding of glycyrrhetinic acid to the rat liver membrane. Biochim. Biophys. Acta 1991, 1066, 77-82. [CrossRef]

27. Lin, A.; Liu, Y.; Huang, Y.; Sun, J.; Wu, Z.; Zhang, X.; Ping, Q. Glycyrrhizin surface-modified chitosan nanoparticles for hepatocyte-targeted delivery. Int. J. Pharm. 2008, 359, 247-253. [CrossRef]

28. Mao, S.-J.; Bi, Y.-Q.; Jin, H.; Wei, D.-P.; He, R.; Hou, S.-X. Preparation, characterization and uptake by primary cultured rat hepatocytes of liposomes surface-modified with glycyrrhetinic acid. Pharmazie 2007, 62, 614-619. [CrossRef]

29. Tian, Q.; Zhang, C.-N.; Wang, X.-H.; Wang, W.; Huang, W.; Cha, R.-T.; Wang, C.-H.; Yuan, Z.; Liu, M.; Wan, H.-Y.; et al. Glycyrrhetinic acid-modified chitosan/poly(ethylene glycol) nanoparticles for liver-targeted delivery. Biomaterials 2010, 31, 4748-4756. [CrossRef]

30. Wielgat, P.; Rogowski, K.; Niemirowicz-Laskowska, K.; Car, H. Sialic Acid-Siglec Axis as Molecular Checkpoints Targeting of Immune System: Smart Players in Pathology and Conventional Therapy. Int. J. Mol. Sci. 2020, 21, 4361. [CrossRef]

31. Liu, Y.C.; Yu, M.M.; Chai, Y.F.; Shou, S.T. Sialic Acids in the immune Response during Sepsis. Front. Immunol. 2017, 8, 8. [CrossRef] [PubMed]

32. Hu, J.B.; Kang, X.Q.; Liang, J.; Wang, X.J.; Xu, X.L.; Yang, P.; Ying, X.Y.; Jiang, S.P.; Du, Y.Z. E-selectin-targeted Sialic Acid-PEGdexamethasone Micelles for Enhanced Anti-Inflammatory Efficacy for Acute Kidney Injury. Theranostics 2017, 7, 2204-2219. [CrossRef] [PubMed]

33. Li, R.; Qiao, S.L.; Chen, X.X.; Xing, G.X.; Li, X.W.; Zhang, G.P. Vesicular stomatitis virus glycoprotein suppresses nuclear factor kappa-B- and mitogen-activated protein kinase-mediated pro-inflammatory responses dependent on sialic acids. Int. J. Biol. Macromol. 2020, 152, 828-833. [CrossRef] [PubMed]

34. Hu, L.; Luo, X.; Zhou, S.L.; Zhu, J.Y.; Xiao, M.Y.; Li, C.; Zheng, H.L.; Qiu, Q.J.; Lai, C.Y.; Liu, X.R.; et al. Neutrophil-Mediated Delivery of Dexamethasone Palmitate-Loaded Liposomes Decorated with a Sialic Acid Conjugate for Rheumatoid Arthritis Treatment. Pharm. Res. 2019, 36, 15. [CrossRef] [PubMed]

35. Xu, X.-L.; Shu, G.-F.; Wang, X.-J.; Qi, J.; Jin, F.-Y.; Shen, Q.-Y.; Ying, X.-Y.; Ji, J.-S.; Du, Y.-Z. Sialic acid-modified chitosan oligosaccharide-based biphasic calcium phosphate promote synergetic bone formation in rheumatoid arthritis therapy. J. Control. Release 2020, 323, 578-590. [CrossRef]

36. Uchiyama, S.; Sun, J.; Fukahori, K.; Ando, N.; Wu, M.Y.; Schwarz, F.; Siddiqui, S.S.; Varki, A.; Marth, J.D.; Nizet, V. Dual actions of group B Streptococcus capsular sialic acid provide resistance to platelet-mediated antimicrobial killing. Proc. Natl. Acad. Sci. USA 2019, 116, 7465-7470. [CrossRef]

37. Li, C.; Qiu, Q.J.; Liu, M.; Liu, X.R.; Hu, L.; Luo, X.; Lai, C.Y.; Zhao, D.; Zhang, H.X.; Gao, X.; et al. Sialic acid-conjugate modified liposomes targeting neutrophils for improved tumour therapy. Biomater. Sci. 2020, 8, 2189-2201. [CrossRef]

38. Xu, X.L.; Lu, K.J.; Zhu, M.L.; Du, Y.L.; Zhu, Y.F.; Zhang, N.N.; Wang, X.J.; Kang, X.Q.; Xu, D.M.; Ying, X.Y.; et al. Sialic Acid-Functionalized pH-Triggered Micelles for Enhanced Tumor Tissue Accumulation and Active Cellular Internalization of Orthotopic Hepatocarcinoma. ACS Appl. Mater. Interfaces 2018, 10, 31903-31914. [CrossRef]

39. Schauer, R. Sialic acids as regulators of molecular and cellular interactions. Curr. Opin. Struct. Biol. 2009, 19, 507-514. [CrossRef]

40. Nair, R.; Reddy, B.H.; Kumar, C.A.; Kumar, K.J. Application of chitosan microspheres as drug carriers: A review. J. Pharm. Sci. Res. 2009, 1, 1-12.

41. Kurita, K.; Kamiya, M.; Nishimura, S.-I. Solubilization of a rigid polysaccharide: Controlled partial N-Acetylation of chitosan to develop solubility. Carbohydr. Polym. 1991, 16, 83-92. [CrossRef] 
42. Sugimoto, M.; Morimoto, M.; Sashiwa, H.; Saimoto, H.; Shigemasa, Y. Preparation and characterization of water-soluble chitin and chitosan derivatives. Carbohyd. Polym. 1998, 36, 49-59. [CrossRef]

43. Yang, T.C.; Chou, C.C.; Li, C.F. Preparation, water solubility and rheological property of the $N$-alkylated mono or disaccharide chitosan derivatives. Food Res. Int. 2002, 35, 707-713. [CrossRef]

44. Rui, L.Y.; Xie, M.H.; Hu, B.; Zhou, L.; Saeeduddin, M.; Zeng, X.X. Enhanced solubility and antioxidant activity of chlorogenic acid-chitosan conjugates due to the conjugation of chitosan with chlorogenic acid. Carbohydr. Polym. 2017, 170, 206-216. [CrossRef]

45. Huang, W.-T.; Chang, M.-C.; Chu, C.-Y.; Chang, C.-C.; Li, M.-C.; Liu, D.-M. Self-assembled amphiphilic chitosan: A timedependent nanostructural evolution and associated drug encapsulation/elution mechanism. Carbohydr. Polym. 2019, 215, 246-252. [CrossRef]

46. Mu, Y.; Wu, G.; Su, C.; Dong, Y.; Zhang, K.; Li, J.; Sun, X.; Li, Y.; Chen, X.; Feng, C. pH-sensitive amphiphilic chitosan-quercetin conjugate for intracellular delivery of doxorubicin enhancement. Carbohydr. Polym. 2019, 223, 115072. [CrossRef]

47. Schlachet, I.; Trousil, J.; Rak, D.; Knudsen, K.D.; Pavlova, E.; Nystrom, B.; Sosnik, A. Chitosan-graft-poly (methyl methacrylate) amphiphilic nanoparticles: Self-association and physicochemical characterization. Carbohydr. Polym. 2019, 212, 412-420. [CrossRef]

48. Almeida, A.; Araujo, M.; Novoa-Carballal, R.; Andrade, F.; Goncalves, H.; Reis, R.L.; Lucio, M.; Schwartz, S., Jr.; Sarmento, B. Novel amphiphilic chitosan micelles as carriers for hydrophobic anticancer drugs. Mater. Sci. Eng. C 2020, 112. [CrossRef]

49. Liu, Q.; Li, Y.; Yang, X.; Xing, S.; Qiao, C.; Wang, S.; Xu, C.; Li, T. O-Carboxymethyl chitosan-based pH-responsive amphiphilic chitosan derivatives: Characterization, aggregation behavior, and application. Carbohydr. Polym. 2020, 237. [CrossRef]

50. Yan, T.; Li, C.; Ouyang, Q.; Zhang, D.; Zhong, Q.; Li, P.; Li, S.; Yang, Z.; Wang, T.; Zhao, Q. Synthesis of gentamicin-grafted-chitosan with improved solubility and antibacterial activity. React. Funct. Polym. 2019, 137, 38-45. [CrossRef]

51. Liang, F.; Li, C.; Hou, T.; Wen, C.; Kong, S.; Ma, D.; Sun, C.; Li, S. Effects of Chitosan-Gentamicin Conjugate Supplement on Non-Specific Immunity, Aquaculture Water, Intestinal Histology and Microbiota of Pacific White Shrimp (Litopenaeus vannamei). Mar. Drugs 2020, 18, 419. [CrossRef] [PubMed]

52. Xu, C.; Guan, S.; Xu, J.Q.; Gong, W.T.; Liu, T.Q.; Ma, X.H.; Sun, C.K. Preparation, characterization and antioxidant activity of protocatechuic acid grafted carboxymethyl chitosan and its hydrogel. Carbohyd. Polym. 2020, 252, 117210. [CrossRef] [PubMed]

53. Fathi, M.; Barar, J.; Erfan-Niya, H.; Omidi, Y. Methotrexate-conjugated chitosan-grafted pH- and thermo-responsive magnetic nanoparticles for targeted therapy of ovarian cancer. Int. J. Biol. Macromol. 2020, 154, 1175-1184. [CrossRef] [PubMed]

54. Zhang, M.; Cheng, H.; Gong, Z.; Zhang, J.; Liu, X.; Wang, B.; Ban, L.; Zeng, Y.; Zhu, Z. Fabrication of Chitosan-18ß-Glycyrrhetinic Acid Modified Titanium Implants with Nanorod Arrays for Suppression of Osteosarcoma Growth and Improvement of Osteoblasts Activity. Adv. Funct. Mater. 2017, 27, 1703932. [CrossRef]

55. Fischer, D.; Li, Y.; Ahlemeyer, B.; Krieglstein, J.; Kissel, T. In vitro cytotoxicity testing of polycations: Influence of polymer structure on cell viability and hemolysis. Biomaterials 2003, 24, 1121-1131. [CrossRef]

56. Mattson, G.; Conklin, E.; Desai, S.; Nielander, G.; Savage, M.D.; Morgensen, S. A practical approach to crosslinking. Mol. Biol. Rep. 1993, 17, 167-183. [CrossRef]

57. Du, H.; Yang, X.; Pang, X.; Zhai, G. The synthesis, self-assembling, and biocompatibility of a novel O-carboxymethyl chitosan cholate decorated with glycyrrhetinic acid. Carbohydr. Polym. 2014, 111, 753-761. [CrossRef]

58. Hakimi, S.; Mortazavian, E.; Mohammadi, Z.; Samadi, F.Y.; Samadikhah, H.; Taheritarigh, S.; Tehrani, N.R.; Rafiee-Tehrani, M. Thiolated methylated dimethylaminobenzyl chitosan: A novel chitosan derivative as a potential delivery vehicle. Int. J. Biol. Macromol. 2017, 95, 574-581. [CrossRef]

59. Sgouras, D.; Duncan, R. Methods for the evaluation of biocompatibility of soluble synthetic polymers which have potential for biomedical use: 1-Use of the tetrazolium-based colorimetric assay (MTT) as a preliminary screen for evaluation ofin vitro cytotoxicity. J. Mater. Sci. Mater. Med. 1990, 1, 61-68. [CrossRef]

60. Kean, T.; Roth, S.; Thanou, M. Trimethylated chitosans as non-viral gene delivery vectors: Cytotoxicity and transfection efficiency. J. Control. Release 2005, 103, 643-653. [CrossRef]

61. Huang, Y.; Ding, X.; Qi, Y.; Yu, B.; Xu, F.J. Reduction-responsive multifunctional hyperbranched polyaminoglycosides with excellent antibacterial activity, biocompatibility and gene transfection capability. Biomaterials 2016, 106, 134-143. [CrossRef] [PubMed] 